\title{
New correlations for the prediction of double-mix phase chart characteristics components of energy materials
}

\author{
(C) Vladimir N. Popok, ${ }^{+}$and Vladimir A. Shandakov \\ Altai Federal Research and Production Center. Socialist St.. 1. Bijsk, 659322. Altai Region. Russia. \\ Phone: +7 (3854) 30-19-37. Email:vnpopok@mail.ru
}

\begin{abstract}
${ }^{*}$ Supervising author; ${ }^{+}$Corresponding author
Keywords: components of mixed energy materials, eutecism, co-crystallizates, phase charts, correlation ratios, melting temperature, component ratio.
\end{abstract}

\begin{abstract}
Special phase diagram points (eutecism, peritectics, co-crystallizates) of double (generally multi-component) mixtures of energy material components characterize the states and properties of mixtures some interest to mixed energy materials. The construction of phase charts in the form of the dependence of melting temperature on the content of components in the mixture is based on experimental data. The Schroeder equation is traditionally used to predict special points (melting and component content at eutecical, peritic, socrystalsitis) and approximation of experimental data. The use of Schroeder's experimental methods and equations is limited by a number of conditions and requirements related to the sodouriability and thermal durability of components and mixtures, the congruence of melting, the kinetic features of melting processes and crystallization. In addition, the use of the Schroeder equation suggests, in general, the presence of experimental data on the temperature and entalpia of melting components and mixtures at special points. Taken together, this determines attempts to predict the properties of mixtures at special points of the lyckued line regarding simple correlations or the use of a modified Schroeder equation in approximation experimental data. This is supposed to use a minimum amount of information for individual components, for example, at melting temperature. By the present time, the positive results of such a hike to determine the ratio of components in double mixtures with one particular point (eutecism) on the lyckeudus line have been published.

In this study, new correlations have been obtained for the forecast of the melting rate of double mixtures at special points of the liquidus line containing eutecicism, eutecicism and peritectomy, two eutecics and a point of component co-crystalization. This uses data only on the melting temperature of individual components of mixtures. The resulting high correlation ratios $(\mathrm{R}) \mathrm{R}^{2} \approx 0.94$ are consistent with the results of the use of Schroeder equations with the temperature and entalphee of melting components and mixtures. this, the sustainability of the correlations in publications was assessed, while expanding the sample size of components from other classes.
\end{abstract}

\section{References}

[1] O. Bolton, L.R. Simke, P.F. Pagoria, A.J. Matzger. High Power Explosive with Good Sensitivity: A 2:1 Cocrystal of CL-20:HMX. Cryst. Growth Des. 2012. No.12(9). P.4311-4314.

[2] V.N. Popok, and N.V. Bychin. Properties thermoreversible cocrystals with a low temperature of melting on a basis hexanitrohexaazaisowurtzitane. Butlerov Communications. 2014. Vol.37. No.2. P.39-52. ROI: jbc-02/14-37-2-39

[3] E. Boyer, P.W. Brown, K.K. Kuo. Solid Solution Formation between RDX and Common Solid Propellant Binders. Challenges in Propellants and Combustion 100 Years After Nobel. 1997.

[4] R.D. Chapman, J.W. Fronabarger. A Convenient Correlation for Prediction of Binary Eutectics Involving Organic Explosives. Propellants, Explosives, Pyrotechnics. 1998. Vol.23. No.1. P.50-55.

[5] J. Sangster. Phase Diagrams and Thermodinamic Properties of Binary and Ternary Systems on Nitroaromatic Compounds. J. Phys. Chem. Ref. Data. 1997. Vol.26. No.2. P.351-502.

[6] T. Urbanski. Chemistry and Technology of Explosives. Pergamon Press, New York. 1964. Vol. II and III.

[7] R.D. Chapman, J.W. Fronabarger, W.B. Sanborn, G. Burr, S. Knueppel. Phase Behavior in TNAZ-Based and Other Explosive Formulations. Report TPL-FR-2049, TPL, Inc., Albuquerque, NM, USA; ADA286004. 1994. 
NEW CORRELATIONS FOR THE PREDICTION OF DOUBLE-MIX PHASE CHART CHARACTERISTICS...

[8] L.A. Belfiore, C.K.S. Lee, J. Tang. The influence of competitive interactions on multiple eutectic phase behavior in poly(ethylene oxide) molecular complexes. Polymer 44. 2003. P.3333-3346. www.elsevier.com/locate/polymer.

[9] V.N. Popok, N.V. Bichyn, N.I. Popok, and N.V. Shein. Mechanical activation of co-crystallization of some nitro compounds. Butlerov Communications. 2013. Vol.34. No.5. P.106-123. ROI: jbc-02/13-34-5106 